\title{
Confluências
}

\section{POR E PARA MULHERES: uma análise sobre a atuação das parlamentares da ALERJ, de 2015 a 2018}

\author{
Naiara Coelho \\ Universidade Federal Fluminense (UFF)
}

\begin{abstract}
RESUMO
Sob o contexto de diminuição do percentual de mulheres nos parlamentos e retirada de direitos das brasileiras, esta pesquisa analisa a atuação das deputadas da Assembleia do Estado do Rio de Janeiro (ALERJ), por meio da produção legislativa das parlamentares mulheres para mulheres, em relação às Audiência Públicas, ambas realizadas durante a legislatura que compreende os anos de 2015 à 2018. Para isso realiza-se uma investigação acerca da existência de relação entre os temas das Audiências Públicas, realizadas pela Comissão de defesa dos Direitos da Mulher, e a produção legislativa das parlamentares da Casa, como um diagnóstico de planos e estratégias possíveis de atuação parlamentar pró direitos das mulheres. Essa análise parte das críticas feministas à representação política institucional.
\end{abstract}

Palavras-chave: Representação Política. Mulheres. Feminismo.

\section{FOR AND TO WOMEN: an analysis on ALERJ'S parliamentary action from 2015 to 2018}

\begin{abstract}
Under the context of the decrease in the percentage of women in the parliaments and the withdrawal of rights from Brazilian women, this study analyzes the performance of MPs from the Assembly of the State of Rio de Janeiro (ALERJ), through the legislative production of women parliamentarians for women, in relation to to the Public Hearing, held during the legislature that covers the years 2015 to 2018. For this, an investigation is carried out on the existence of a relationship between the themes of the Public Hearings held by the Commission for the Defense of Women's Rights and the legislative production of House parliamentarians, as a diagnosis of possible plans and strategies for parliamentary action for women's rights. This analysis starts from feminist critiques of institutional political representation.
\end{abstract}

Keywords: Political Representation. Women. Feminism. 


\section{INTRODUÇÃO}

Desde o início dos anos 2000, quando as primeiras políticas de especial atenção às mulheres tomaram espaço no âmbito federal, foi possível observar uma oportunidade para concretizar pautas levantadas tanto pelo movimento de mulheres quanto pelo movimento feminista brasileiro, através da política institucional.

Desde a criação da Secretaria de Políticas para as Mulheres, em 2003; a promulgação da lei de violência doméstica, em 2006, (Lei Maria da Penha); até 2011, quando foi eleita a primeira mulher presidenta do Brasil, Dilma Rousseff, houve maior articulação entre os movimentos feministas e de mulheres, trazendo expectativas de mudança concretas na vida das brasileiras.

A segunda década dos anos 2000, no entanto, mostrou que esses avanços não foram profundos o suficiente para transformar a condição de vida das brasileiras.

As eleições de 2014, neste contexto, refletiram as redefinições da política brasileira. Campanhas enfatizando o combate a corrupção, a aposta nos novos rostos e jeitos de fazer política e a diminuição do percentual de mulheres eleitas para os parlamentos brasileiro foram características desse momento.

Além disso, em 2015, o processo de afastamento de Dilma Rousseff foi marcado por forte teor misógino. Em 2016, a Secretaria de Políticas para Mulheres, que havia reunido importantes dados e realizado inúmeros projetos e pesquisas pró direitos das mulheres, foi extinta. Em 2017, Marielle Franco, vereadora do Rio de Janeiro negra, lésbica e favelada foi morta por milicianos ligados à estrutura de poder do Estado, com indícios inclusive da sua relação com familiares do atual presidente.

Este processo violento de retirada dessas duas mulheres de seus cargos políticos deve ser compreendido com maior profundidade, já que o número de participação feminina na política é bastante baixo e, ainda sim, incomoda a estrutura de poder estabelecida.

No âmbito internacional, dentre 190 países, o Brasil é o $152^{\circ}$ no ranking de mulheres na política; e, dentre os 33 países da América Latina, o Brasil ocupa a $32^{\circ}$ posição (IPU, 2018). No âmbito nacional, as mulheres compõem apenas 12\% (638) das chefes de Prefeitura; 14\% (7.812) das câmaras de vereadoras; $7 \%$ (1) chefe do governo estadual; 19\% (5) do senado; 10\% (51) deputadas federais; e, 11\% (114) deputadas estaduais (IBGE, 2018).

Essa realidade se repete nos âmbitos estaduais. No estado do Rio de Janeiro, durante esta pesquisa haviam $11 \%$ (9) prefeitas; $9 \%$ (106) vereadoras; 0\% (0) senadoras; $13 \%$ (6) deputadas federais; e, $11 \%$ (8) deputadas estaduais. Poucas foram as deputadas reeleitas nas eleições de $2014 \mathrm{e}$ o número de mulheres na Assembleia do Estado do Rio de Janeiro (ALERJ) teve o menor percentual dos últimos vinte e quatro anos. 
Isso significa dizer que tanto as decisões tomadas para o país quanto para o estado do Rio de Janeiro vêm, majoritariamente, de perspectivas masculinas, pois são os homens que mais ocupam os cargos políticos e, consequentemente, representam seus interesses políticos.

Todas estas informações motivam o presente artigo. Analisar a atuação de parlamentares na produção legislativa para mulheres converge para com a preocupação com os rumos do que é defendido por/com/para mulheres dentro e fora da política institucional brasileira ${ }^{1}$. Ademais, importante também compreender como se dão as estratégias para a garantia e efetivação dos direitos das mulheres.

A partir desse contexto, o artigo se desenvolve com base em alguns pressupostos. Um deles é o de que esse estudo pode ser compreendido como uma avaliação de parlamentos brasileiros, mas se trata especificamente da experiência carioca. Também constitui um pressuposto a compreensão de que ter mulheres decidindo os rumos da vida pública é essencial para todas as questões sociais que afetam o Brasil ${ }^{2}$.

Isso porque, suas perspectivas traduzem a voz pública de seus corpos, cujas vivências experienciam e representam necessidades e demandas específicas das mulheres.

Outro pressuposto está na especial relevância da voz das mulheres na definição de questões especificamente ligadas a elas, tais como as pautas e projetos a respeito de violência sexual e doméstica, maternidade e contracepção - uma vez que são questões inerentemente ligadas à experiência de ser mulher biológica e socialmente.

Assim sendo, este trabalho apresenta o recorte de um trabalho maior ${ }^{3}$. A partir de uma pesquisa ampla sobre produção legislativa por e para mulheres, aqui, analisa-se a relação entre Audiências Públicas e produção legislativa por e para mulheres, através do exame da atuação das parlamentares mulheres da Assembleia do Estado do Rio de Janeiro, na legislatura que corresponde aos anos de 2015, 2016, 2017 e 2018.

Os aspectos teóricos que embasam essa análise decorrem das teorias feministas norteamericanas $^{4}$ e a partir da categoria de Representação Política Por Perspectiva, de Iris Marion Young (2000).

\footnotetext{
${ }^{1}$ Para esta pesquisa foram consideradas parlamentares ("por") mulheres todas que assim se declaram, o que convergiu em mulheres cisgênero e heterossexuais. Com relação às mulheres sujeitas das políticas propostas ("para") foram consideradas cis, trans, hetero e homossexuais, de acordo com o que as próprias legislações definiam.

2 Apesar da existência e reconhecimento de que homens também propõem leis para mulheres, aqui, optou-se por analisar apenas a atuação das parlamentares mulheres.

${ }^{3}$ A pesquisa a que se refere trata da dissertação de mestrado intitulada "Por e para mulheres: uma análise sobre a produção legislativa das deputadas da ALERJ, entre 2015 e 2018.”, desenvolvida por essa autora, no Programa de PósGraduação em Sociologia e Direito da Universidade Federal Fluminense e finalizada no ano de 2019.

${ }_{4}$ Tendo em vista o recorte realizado para apresentação da pesquisa em artigos, ressalto que além dessas, foram utilizadas como referências teóricas indispensáveis a chegada dessas interpretações as leituras de SAFFIOTI (2015); PATEMAN (1996); BIROLI (2014); CRENSHAW (2002); HIRATA (2009); BENHABIB (1987); entre outras feministas brasileiras e norte-americanas que discutem este tema.
} 
Desta maneira, considerando a experiência parlamentar dentro de um sistema e uma instituição patriarcal, investiga-se como as oito parlamentares da ALERJ, eleitas para a legislatura de 2015-2018, representam as demandas femininas na articulação entre Audiências Públicas e produção legislativa para mulheres.

\section{TEORIA POLÍTICA FEMINISTA E REPRESENTAÇÃO}

A partir do arcabouço das teorias políticas clássica e contemporânea as teorias políticas feministas apresentam suas contribuições críticas à questão da representação política, tendo como objetivo possibilitar que mais mulheres - e outros grupos minoritários - sejam politicamente representadas.

Iris Marion Young (2000) desenvolve dentro da discussão da Teoria Política Feminista a análise da representação como um instrumento para o atendimento político das demandas das minorias. Ela propõe uma alternativa à política de ideias (representação por convicções políticas) e/ou política de presença (representação por presença física), desenvolvida por outras teóricas, como Anne Phillips ${ }^{5}$ (2001).

Para Young, a representação política possui caráter relacional, sendo decorrente da experiência das atrizes políticas antes do exercício parlamentar. Desse modo a autora insere na discussão da representação o conceito de perspectiva social.

A abordagem da representação por perspectiva tem por objetivo não pressupor definições. Afastando-se da rigidez de uma "representação de mulher" ou "representação feminina", demonstra que o debate sobre essencialismo nas identidades também não deve ser distanciado na construção da concepção de Representação.

Assim, é o caráter relacional e influenciado pela experiência (individual ou estrutural) vivenciada pelas sujeitas que traz à arena política aspectos relevantes para a representação, e não uma preconcepção dos interesses e compreensões de tais indivíduas. Assim, perspectiva é defina por Young como:

[um] conjunto de questões, experiências e pressupostos mediante os quais mais propriamente se iniciam raciocínios do que se extraem conclusões. (...) [Portanto] A perspectiva social é o ponto de vista que os membros de um grupo mantêm sobre os processos sociais em função das posições que neles ocupam (Young 2006:164).

Dessa maneira, é possível pensar a perspectiva social para a análise da representação para mulheres nesta pesquisa, pois as mulheres são marcadas social e biologicamente por uma estrutura que as propicia experiências diferenciadas em processos sociais, de forma que a Representação por

\footnotetext{
${ }^{5}$ Mais sobre Política de ideia e política de presença pode ser encontrado em: PHILLIPS, A. De uma política de idéias a uma política de presença? 2001. Revista Estudos Feministas, v. 9, n. 1, p. 268-290, 2001.
} 
Perspectiva de mulheres poderia ser defendida para promover o debate e propostas políticas, a partir de pontos de vista que são próprios da experiência feminina (Young 2000).

Isso consiste em um grande ganho para as decisões políticas, pois estas devem refletir os pontos de vista da sociedade - portanto, também das mulheres.

As mulheres, enquanto grupo social estrutural, "têm experiências semelhantes que apenas os membros de seus próprios grupos podem compreender com o mesmo imediatismo” (Young 2000: 172), o que permite afirmar que é a experiência vivida por mulheres que possibilita maior sensibilização ao que diz respeito à sua vida.

Essa sensibilidade e aproximação dos temas, não deve, entretanto, ser confundida com a essencialização. O fato de a perspectiva ser considerada um ponto de partida - não de chegada (Young 2000) -, permite que, em determinados casos, membras de um mesmo grupo social se articulem sobre um mesmo tema e a partir dele, cada uma tenha uma diferente proposta de concretização ou de solução.

A ideia de que grupos minoritários devem ser homogêneos em seus posicionamentos também revela a conveniência racista de entender pessoas com as mesmas características como um bloco uníssono (Almeida 2018). Situações em que membras de um membro grupo divergem não são vistas como resultado de experiências plurais que geram diferentes posicionamentos. Assim, a redução da possibilidade de discordância à simples falta de articulação política revela tanto as posições contrárias ao desenvolvimento das políticas pró minorias, quanto a necessidade de reprodução das diferentes formas de violência a que são submetidas (Almeida 2018).

Isso porque, o compromisso político da representante com o grupo a que pertence e com as demais minorias sociais não significa ter o poder de transformar, estruturalmente, instituições que se utilizam das discriminações para se manter no poder (Almeida, 2018).

$\mathrm{Na}$ política institucional essas limitações se concretizam pelas normas de funcionamento tanto do sistema eleitoral quanto dos próprios regimentos internos, com uma lógica política que demandam um nível tão sofisticado de organização que as minorias - da forma como são "inseridas" - continuam com dificuldades abissais de concretizar seu papel de representante.

Assim, é importante compreender a representação dentro dos seus limites e buscar as ferramentas conceituais e metodológicas que nos permitam não só analisar a representação de mulheres na política institucional, mas apontar para seus desafios e potencialidades nas lutas presentes e futuras.

Portanto, as ferramentas aqui debatidas sobre a representação por perspectiva social, adaptadas ao contexto brasileiro, podem servir de instrumento para uma análise crítica e relacional da unidade empírica de investigação das mulheres parlamentares da ALERJ, descrita a seguir. 


\section{A REPRESENTAÇÃo POLÍTICA BASEADA NA RELAÇÃO ENTRE AUDIÊNCIAS PÚBLICAS E PROPOSIÇÕES LEGISLATIVAS}

Para a análise das Audiências Públicas e da Produção legislativa foram coletados dados presentes no site oficial da ALERJ, repositório eletrônico oficial da Casa Legislativa. Dessa plataforma foram retiradas informações sobre as oito parlamentares - aqui identificada pelas letras A, B, C, D, E, F e H - além das informações sobre as Audiências Públicas realizadas e Proposições legais de todo o período.

Durante a legislatura analisada foram realizadas vinte e nove Audiências. Dezoito delas estavam transcritas e por isso puderam ser analisadas detalhadamente. Referente às onze audiências não documentadas, foi disponibilizado apenas o tema e a data.

As Audiências Públicas analisadas foram realizadas pela Comissão de Defesa dos Direitos da Mulher (CDDM), órgão institucional da ALERJ responsável pela análise de todas as proposições e realização de Audiências Públicas que versarem sobre mulheres.

A partir da seleção dessas audiências foi realizado um comparativo entre os temas abordados em Audiências Públicas e nas Proposições legais ${ }^{6}$, bem como uma análise sobre a possível relação entre os eventos e as propostas.

A análise do tema das legislações propostas pelas parlamentares e das Audiências Públicas realizadas pela CDDM - comparando com as proposições - permitem inferir um caráter progressista das Audiências em relação à legislação. As nomenclaturas utilizadas e as profissionais e militantes convidadas a falar nas Audiências Públicas demonstram articulação politizada desses eventos: temas como "Cultura do estupro" e "Misoginia" e a compreensão de transexuais como mulheres, por exemplo, não fazem parte do vocabulário utilizado nas produções legislativas da maior parte das parlamentares mas foram discutidos nas audiências pelas convidadas.

As Audiências Públicas contaram com convidadas de diferentes setores da sociedade: acadêmicas, militantes, representantes do governo ou funcionárias públicas (ALERJ 2018), o debate girava em torno de pessoas com diferentes campos de atuação e formas de contribuir para a questão colocada.

Dessa maneira, as Audiências Públicas nos parecem próximas do que Young (2006) afirma como Representação de Perspectiva. Se representar uma perspectiva significa apresentar pontos de partida de uma deliberação, foi também na troca entre sociedade civil, parlamentares e especialistas - convidadas das Audiências Públicas - que ela aconteceu.

\footnotetext{
${ }^{6}$ Os temas das proposições legais foram classificados em quatro grandes áreas: Saúde, Violência, Reconhecimento e Redistribuição. Numa análise comparativa com o tema das Audiências públicas visou-se a compreender, para além dos temas, o próprio caráter dos debates nos eventos. Foi isso que permitiu, por exemplo, considerar as Audiências mais ou menos "progressistas" em relação à legislação.
} 
Assim, o que se destaca - e destoa - nas Audiências Públicas foi a polêmica e especificidade crítica dos assuntos abordados. Para além da visão abstrata dos Projetos de Lei, as Audiências abordam questões específicas da experiência das mulheres, que fogem ao "perfil de mulher" abarcado pela legislação proposta pelas parlamentares.

São exemplos as Audiências Públicas sobre: Condições das gestantes no sistema prisional; Gestantes vivendo com HIV/AIDS, seus direitos sexuais e reprodutivos; Mulheres encarceradas; Seminário Misoginia como indutor do Feminicídio; Cultura do estupro e; Como atuar junto a mulher lésbica e transexual na luta contra o câncer de mama, respeitando sua diversidade.

Nesses exemplos são nomeadas e visibilizadas mulheres que desviam do padrão patriarcal esperado. Não são as mulheres heterossexuais, casadas e mães. Nessa situação, são mulheres lésbicas, transexuais, que cometeram crimes e que possuem doenças sexualmente transmissíveis.

Essas mulheres - sobretudo as transexuais e lésbicas - fazem partes de minorias marginalizadas da sociedade, que necessitam e não possuem assistência pública em experiências básicas do seu cotidiano (Carrieri; Souza; Aguiar 2014).

Nos Projetos de Lei esses temas não aparecem ou aparecem com propostas superficiais frente aos problemas relatados em Audiência.

Sobre as mulheres encarceradas, muitas denúncias feitas durante a Audiência: os relatos apontavam para a péssimas condições físicas do presídio feminino; o despreparo e desrespeito das agentes e funcionárias; a inexistência de atendimento médico e medicamentos; o risco para as gestantes presas por estarem naquelas condições; o processo violento das mulheres que dão à luz no presídio ou no hospital, mas ainda sob custódia, entre outros.

Os Projetos de Lei sobre mulheres encarceradas são os que mais correspondem aos encaminhamentos da Audiência. Eles preveem uma unidade de mamografia móvel para atendê-las; anotação de gravidez e filhos no registro de prisão ou ocorrência e; a exclusividade de agentes femininas em unidades socioeducativas para meninas.

Já com relação à Cultura do Estupro, as sete legislações que abarcam o tem de violência sexual o fazem a partir de programas de reparação para a vítima, criação de espaços de atendimento e punição aos autores e menos com o caráter pedagógico ou educativo para se pensar a prevenção.

Com relação às mulheres transexuais, o único projeto especificamente ligado a elas trata da anotação de identidade de gênero e nome social em ocorrências policiais.

Para as mulheres lésbicas, além do projeto de lei citado acima, que prevê também a anotação da orientação sexual, há um projeto que visa o reconhecimento da união estável homoafetiva como entidade familiar nos programas de habitação popular.

Não foram encontradas propostas sobre HIV/AIDS em mulheres, sejam elas gestante ou não. 
Apesar de não serem transformativas (Fraser 2015), as proposições sobre mulheres lésbicas e transexuais atendem a uma das demandas do movimento LBT (Lésbicas, Bissexuais e Transexuais), que corresponde à construção de dados para que seja possível fazer mapeamentos dessa população invisibilizada (Peres; Soares; Dias 2018).

Essas audiências significaram uma forma de apresentar perspectivas femininas invisibilizadas na sociedade e na legislação produzida pela ALERJ. As convidadas de cada uma das audiências traduziam suas vivências e pesquisas com relação ao tema como representantes reais ou simbólicas dessas causas.

Às deputadas cabia a função de representar politicamente essas demandas transformandoas em legislação.

Na nossa avaliação, essa estratégia corresponde, empiricamente, a uma alternativa para o falso dilema de representação, pelo qual se afirma que "Somente pessoas com certos atributos descritivos podem representar a perspectiva de um grupo social estrutural” (Young 2006: 179).

Pois, ainda que a representante não possua esses atributos descritivos, ela pode, através de um processo de consciência e localização das relações sociais, compreender e representá-las (Young 2006). Conforme a autora:

é possível - ainda que eu não considere muito comum - que uma pessoa desprovida dos atributos descritivos represente uma perspectiva. Para tanto, porém, é preciso que ela esteja situada em relações sociais que lhe propiciem experiências e percepções sociais similares às daquela pessoa que possui os atributos descritivos (Young 2006: 179).

Nesse sentido, as Audiências Públicas aparecem como um momento em que as parlamentares podem ser situadas às experiências que não lhes são próprias, oportunizando que elas se conscientizem de outras necessidades da população.

No entanto, essa forma de representação não significa um resultado automático de mudanças e influências. Tendo em vista que se trata de um ponto de partida e de localização de relações sociais, não necessariamente isso resultará em políticas transformativas:

\footnotetext{
Representar um interesse ou uma opinião geralmente envolve promover certos desdobramentos específicos no processo de tomada de decisões, ao passo que representar uma perspectiva geralmente significa promover certos pontos de partida para a discussão. A partir de uma determinada perspectiva social um representante coloca certos tipos de questões, relata certos tipos de experiência, retoma uma determinada linha de narrativa histórica ou expressa um certo modo de olhar as posições de outrem. Isso contribui decisivamente para a inclusão de diferentes pessoas no processo de tomada de decisões e chama a atenção para possíveis efeitos das políticas propostas sobre os diferentes grupos. No entanto, expressar uma perspectiva quase nunca significa inferir uma conclusão sobre resultados (Young 2006: 167/168). grifo da autora.
}

Visando analisar essa possível “conclusão sobre resultados” (Young 2006: 168), a sessão abaixo analisa a relação temática e temporal entre as Audiências Públicas realizadas pela Comissão 
de Defesa dos Direitos da Mulher e a produção legislativa das parlamentares, durante o mandato investigado.

\section{A CONSEQUÊNCIA LEGISLATIVA DAS AUDIÊNCIAS PÚBLICAS: ANÁliSE DA RELAÇÃO ENTRE AUDIÊNCIAS PÚBLICAS E PROJETOS DE LEI}

Das vinte e nove audiências públicas realizadas, verificando-se a partir da data de publicação, apenas quatro Projetos de Lei derivaram das discussões realizadas em Audiência Pública, ou foram justificadas pelos mesmos motivos da audiência.

Para chegar a essa afirmação, foram analisados os Projetos de Lei com temas semelhantes aos temas das Audiências Públicas e verificado o período de publicação da proposta e a data do evento. Foram consideradas as propostas do mesmo mês de realização das Audiências ${ }^{7}$ e encontrados apenas quatro casos em que haveria essa possível relação.

Embora sejam poucos casos, representam situações em que é possível observar um ganho qualitativo nas propostas legais, pois derivam de uma estratégia mais ampla e decorrente de um espaço formativo para as parlamentares: as Audiências Públicas.

As proposições analisadas possuem diferentes estratégias de autoria: duas são de autoria individual da deputada $\mathrm{H}$ e duas são coletivas. Para compreendê-las serão apresentadas conforme a ordem cronológica das proposições/Audiências.

O Primeiro Projeto de Lei é de autoria da deputada H. Foi publicado em 11 de maio de 2015 e se relaciona com a Audiência Pública sobre o "Dia Internacional da Perda gestacional", realizada dia 15 de maio do mesmo ano. Este Projeto:

DETERMINA QUE AS UNIDADES DE SAÚDE CREDENCIADAS NO SISTEMA ÚNICO DE SAÚDE - SUS, BEM COMO AS DA REDE PRIVADA, OFEREÇAM, LEITO SEPARADO PARA AS MÃES DE NATIMORTO E AS MÃES COM ÓBITO FETAL (PL 1774/2016 In ALERJ 2018).

Além da análise temporal e também do tema da audiência, com a ementa da proposta é possível afirmar a relação entre esses dois elementos, porque durante a audiência - dentre as muitas formas de violência psíquica e obstétrica - a necessidade de um leito para as mães de natimortos, separado das mães que estão com seus bebês, apareceu como uma denúncia e um encaminhamento.

A solicitante dessa Audiência Pública, mãe de um natimorto, relatou em Audiência:

(...) E foi quando eu fui ler os relatos nos grupos, como os do Mães de Anjo, como os do Luto a Luta. E fui ver que a maior parte das mulheres não tem esse privilégio, que eu tive em uma clínica particular. Muitas ficam, ou mesmo em outras clínicas particulares, porque isso não é uma exclusividade do serviço público, isso é muito importante frisar, mesmo em

\footnotetext{
${ }^{7}$ Os casos de correspondência aconteceram com diferença de três ou quatro dias, antes ou após a data da Audiência Pública.
} 
outras clínicas particulares as mulheres ficam na mesma ala da maternidade, após a sua perda.

Recebi o recado, uma mensagem de uma mulher que ficou entre duas mães dando a luz. A mãe que estava do lado direito, o filho, inclusive, tinha o mesmo nome do filho daquela que tinha perdido por uma daquelas coincidências do destino. E nem as mães que estavam dando a luz conseguiam viver aquele momento em sua plenitude, e demonstrar toda a sua alegria, porque também estavam tristes, compartilhando a dor da mãe que tinha acabado de perder o seu filho, e nem aquela mãe podia viver o seu luto.

Além disso, ouvi relatos de mães que receberam enfermeiras dando parabéns, entregando o kit maternidade, entrando no quarto e falando "mas cadê o bebê daqui?" Entrando no quarto e falando: "Ué, mas o seu bebê está na UTI? Ele já vem mamar? Já deu mamar, mamãe?" Assim, uma absoluta falta de cuidado. (...)

Os relatos foram muito impressionantes. Eu acho que as outras falam vão poder trazer aqui os relatos pessoais. E foi isso o que me mobilizou a pedir essa audiência pública, para poder dar visibilidade a esse tema, que é tão silenciado. (Audiência Pública 5/2016).

Confirmando a relação entre Audiência e proposição, verifica-se que a justificativa do Projeto de Lei reforça a necessidade de amparo psicológico à essas mães e reforça que a proposta não traz novas despesas ao Estado, apresentando-se da seguinte maneira:

Hoje, quem perde o bebê antes ou logo após o nascimento, enfrenta, além da dor, o despreparo das estruturas da saúde.

Nesse momento de dor intensa, muitas dessas mulheres sofrem um abalo psicológico sem proporções ao se depararem, no mesmo quarto em que se recuperam, com diversas mães e seus bebês.

Assim, faz-se necessário amenizarmos a dor dessas mães nesse momento tão delicado de suas vidas.

Cabe ressaltar que tal ação não irá gerar custo algum para as unidades de saúde, posto que apenas irão instalar essas mães em quartos separados das demais mães (PL1774/2016 In ALERJ 2018).

Essa situação pode ser usada como um exemplo da produção legislativa a partir de uma demanda real e solicitada pela população. Apesar de proposto dias antes da realização da Audiência, a compreensão dessa realidade como uma necessidade de amparo legal revela uma ligação mais estreita da parlamentar com mulheres do eleitorado. No entanto, este projeto está sem encaminhamentos nas análises de comissões desde 2016 (ALERJ 2018).

A segunda situação trata-se de um Projeto de Lei que foi publicado em 03 de junho de 2016, três dias antes da Audiência Pública. Ambos tratam sobre violência sexual. O tema da Audiência foi "Cultura do Estupro" e o Projeto, que hoje é Lei, prevê:

ESTABELECE MULTA E MANDA RETIRAR DO AR TODA E QUALQUER VEICULAÇÃO PUBLICITÁRIA MISÓGINA, SEXISTA OU ESTIMULADORA DE AGRESSÃO E VIOLÊNCIA SEXUAL NO ÂMBITO DO ESTADO DO RIO DE JANEIRO. (PL 1844/2016 In ALERJ 2018).

Esta proposta é de autoria de todas as deputadas mulheres e alguns deputados homens, quarenta parlamentares no total. A proposta foi aprovada como Lei mais de dois anos depois, em outubro de 2018 (ALERJ 2018).

A relação entre a Audiência Pública e a Lei pode ser observada - para além da temática de violência sexual - também pela fala da deputada D em Audiência: 
É importante que estejamos aqui. Mas é triste sabermos que foi preciso de uma tragédia, como a da jovem de 16 anos, em Jacarepaguá, para unificar os nossos esforços e obrigar a sociedade, os órgãos de segurança, os poderes públicos, os meios de comunicação, a se posicionarem. (...)

Asseguro que as comissões aqui presentes têm absoluto compromisso em barrar a violência sexual e o estupro. Esses ataques ferem brutalmente a integridade física, psíquica, moral e a cidadania plena das mulheres.

Temos apresentado projetos de lei que buscam combater essa realidade. Acho que precisamos atuar a curto, médio e longo prazos, pois se trata de enfrentar uma ideologia milenar que reforça a lógica machista, muitas vezes misógina, que ainda se manifesta em nosso cotidiano.

Em pleno século XXI nos defrontamos diariamente com a barbárie ao saber que acontece um estupro a cada 11 minutos no Brasil. E os anuários sobre violência no estado relatam que, em todas as cidades do interior do Rio de Janeiro apresentam estatísticas assustadoras de estupro. (...)

Por isso, devemos unir as ações dos Legislativos estadual e federal e do Executivo, através de campanhas, projetos de lei e ações que garantam às vítimas que o estado fluminense não admitirá mais a impunidade ou a leniência com esses crimes e, principalmente, garantir o pleno funcionamento da rede de proteção às mulheres, vítimas de violência, que levamos anos para construir minimamente, e que, a pretexto da crise econômica e financeira, estão sendo desmontadas. (Audiência pública 5/2016).

A justificativa dessa proposição ressalta o impacto da mídia no comportamento social. Também informa que a proposição decorre de uma discussão junto de um dos movimentos feministas nacionais:

A figura feminina sempre foi utilizada pela mídia em analogia à submissão, trazendo a ideia machista de que "o lugar da mulher é na cozinha". Desde os primórdios, as "Amélias" são retratadas pela publicidade em propaganda de produtos de limpeza. Porém, com o passar do tempo, a modernidade trouxe novos reflexos da mudança de comportamento, passando a representar a mulher como produto de consumo, ou seja, a mulher passou a ser vista como um produto a ser consumido. Assim, através dela, as propagandas fazem alusões ao erotismo em busca do consumo pelo desejo. (...)

É imprescindível o debate do estereótipo da mulher nas mídias audiovisuais e nas redes sociais, visto que também é por meio dessas mídias que a misoginia, o machismo e o incentivo à violência contra a mulher, em especial, a sexual, se dispersa na sociedade fluminense. A mulher é estereotipada como sendo submissa, ignorante, fraca, objeto de consumo, dentre outros adjetivos agressivos, o que por sua vez influencia no modo com que a sociedade trata as mulheres em seu dia a dia. (...)

O presente projeto de lei nasceu da contribuição das participantes do Seminário produzido pela Comissão de Defesa dos Direitos da Mulher - CDDM da Alerj, em parceria com a União Brasileira de Mulheres - UBM, no último dia 2 de maio de 2016, cuja documentação segue em anexo, sendo certo que esta iniciativa legislativa não tem por objetivo impor qualquer tipo de censura aos produtores de propagandas, coibindo-lhes a criatividade, mas apenas de evitar a veiculação de propagandas que tenham por finalidade depreciar a imagem da mulher ou de estimular a prática de violência contra a mulher (PL 1844/2016, In ALERJ 2018).

O fato desta ser uma proposta de autoria coletiva pode decorrer da controvérsia sobre o próprio tema, pois o PL se coloca contrário a tratamentos violentos que são naturalizados.

Destaque-se que, mesmo com autoria de quarenta (do total de sessenta parlamentares), somente dois anos depois essa proposta foi aprovada como lei. Isso também pode ser levado como um exemplo da resistência em aprovar legislações desse tipo, pois, para isso, é preciso reconhecer que existem um tipo de incentivo e aceitação da violência contra as mulheres que é tolerado pelos 
poderes públicos. Além disso, se coloca contra grupos de empresas que podem inclusive ser parceiros políticos ou figuras influentes no cenário estadual. Exigindo que a proposição tenha estratégias mais sofisticadas para que se transforme em lei.

A terceira proposta, de autoria individual da deputada $\mathrm{H}$, foi publicada em 10 de junho de 2016, quatro dias após a realização da audiência pública sobre "Cultura do Estupro". A proposta determina a:

CRIAÇÃO DE UM CENTRO DE DEFESA DA MULHER NA CASA ONDE OCORREU O ESTUPRO COLETIVO, LOCALIZADA NA COMUNIDADE SÃO JOSÉ OPERÁRIO, NA PRAÇA SECA, ZONA OESTE DO ESTADO DO RIO DE JANEIRO (PL 1887/2016 In ALERJ 2018).

Tanto a Audiência Pública quanto o Projeto de Lei foram motivados por um caso de estupro coletivo, de uma jovem de 16 anos, que repercutiu nos noticiários brasileiros (Folha 2016).

A justificativa da proposta prevê que o espaço criado seja um órgão de auxílio às vítimas e também prevenção:

O objetivo da criação do Centro de Defesa da Mulher, na Comunidade São José Operário, é prevenir e evitar que outros casos de estupro venham a ocorrer e também, fornecer o auxílio necessário às vítimas de violência sexual, oferecendo informações necessárias sobre o crime ocorrido, bem como, o encaminhamento das vítimas, para órgãos que possam promover justiça e proteção às vítimas (PL 1887/2016 In ALERJ 2018).

A proposta visa a ressignificar o local do crime sem apagar a história de violência ali ocorrida. Dentro de uma concepção de acolhimento e prevenção, a proposta se afasta de projetos meramente punitivos que tem como foco agressores e não vítimas. Enquanto que a proposição coletiva, apesar de também tratar sobre violência sexual, possui outra perspectiva sobre o tema, tendo dentre os objetivos principais a punição.

Uma questão importante dessa análise é que a deputada $\mathrm{H}$ não consta como presente nessa Audiência Pública. Ainda assim, possui uma proposta relacionada. Essa pode ser uma forma de demonstrar também formas de atuação e um compromisso que está para além da presença física, mas que pode ser concretizada em atuações objetivas por meio, por exemplo, da assessoria especializada que a deputada possui.

Esta proposta também está sem encaminhamentos, desde a sua proposição.

A quarta proposta, que também é coletiva, permanece como Projeto de Lei pendente de votação. É de autoria de algumas deputadas mulheres e alguns homens, dez parlamentares no total. Relacionada com a Audiência Pública sobre o "Empoderamento da mulher no esporte e na política”, realizada em 13 de junho.

O Projeto de Lei "CRIA A POLÍTICA ESTADUAL DE EMPODERAMENTO DA MULHER E DÁ OUTRAS PROVIDÊNCIAS” (PL 1909/2016 In ALERJ 2018). 
Essa proposta, que prevê uma série de mecanismos e políticas públicas para a valorização das mulheres em espaços masculinizados, - esporte e política - tem como motivação, assim como a audiência pública, o fato de que 2016 foi o ano em que as Olimpíadas ocorreram no Brasil e que houve Eleições municipais. No relato da Audiência consta:

[deputada C] mencionou que foi acordado com a Comissão de Defesa dos Direitos da Mulher, que esta audiência seria para tratar das questões relevantes ao esporte; afirmou que esta Comissão Especial reproduz no Estado do Rio de Janeiro uma estratégia desenvolvida no âmbito do Congresso Nacional, levando em conta que 2016 é um ano de olimpíadas e eleições. Afirmou que, na política, apesar de haver reserva de $30 \%$ de vagas para candidatura de mulheres, essas, muitas vezes, não são preenchidas. Comentou que, na Assembleia Legislativa do Estado do Rio de Janeiro, em 2010, foram eleitas 11 Deputadas e hoje são somente 9 Deputadas. Ponderou que no aspecto do esporte esta diferença se faz de uma forma mais presente, às vezes, invisível. Ressaltou que esta audiência tem como finalidade ouvir todas as pessoas que estão diretamente envolvidas com esporte, recolhendo propostas que serão encaminhadas aos órgãos responsáveis (Audiência Pública 6/2016).

O ano de 2016 também se notabilizou pelo fato da primeira mulher presidenta do Brasil ter sido afastada de seu cargo por meio de um processo misógino que a acusou de crime de responsabilidade (Rubim; Argolo 2018). As Olimpíadas ficaram marcadas pelo alto número de mulheres participantes, $45 \%$ e pela primeira vitória do Brasil ser realizada pela judoca - negra, periférica e lésbica - Rafaela Silva (G1 2016).

O texto de justificativa dessa proposta ressalta a necessidade de igualdade entre homens e mulheres, através da apresentação de alguns aspectos históricos como possíveis causas dessa violência, e também um texto religioso para a refutar.

A história registra a discriminação homem-mulher, em todos os aspectos implantou-se uma visão cultural de que a mulher é inferior ao homem e não pelas oportunidades que lhes foram negadas.

Essa mesma visão não igualitária entre os sexos, que preconiza o masculino com base em preconceitos e estereótipos, provavelmente foi a responsável pela consolidação de uma sociedade machista nos séculos XIX e XX.

Para demonstrar que a mulher tem todos os direitos e garantias iguais as que são dispensadas ao homem, não sendo ela inferior em nada, Deus, "o Senhor Criador de tudo", que criou inclusive o homem, observou que sem a mulher não seria completo e, porque não dizer, "um nada", para que não se tenha dúvida de que são seres iguais, ou seja, um não é superior ao outro, teve o cuidado de criar a mulher da "costela" do homem. Gn. 2.20-23 Dada a relevância de buscarmos corrigir as injustiças perante as mulheres, propomos a presente proposta legislativa objetivando estabelecer a igualdade de tratamento e oportunidades as mulheres (RIO DE JANEIRO, PL1909/2016).

A visualização dessas quatro situações traz diversas possibilidades de inferência. Além da autoria, o tema e o clamor da mídia para situações como essa apareceram em destaque na justificativa dessas proposições.

O modelo de representação política utilizado nessa pesquisa ressalta que a atuação parlamentar, decorrente da troca com o eleitorado, corresponde a um aspecto positivo da representação. Conforme Young: 
Uma vez que não há mandato autorizado para várias decisões, a representação é mais forte quando carrega os vestígios da discussão que levou à autorização ou quando, de outra forma, se justifica persuasivamente numa prestação de contas pública (Young 2006: 156).

Nesse sentido, tendo em vista a baixa proporcionalidade entre as vinte nove audiências públicas e apenas quatro Projetos de Lei gerados com mesmos temas, esse aspecto da representação apareceu de forma bastante frágil na análise da atuação das parlamentares.

Ainda assim, a realização das Audiências Públicas demonstra uma forma mais democrática de fazer política, em que a população é chamada a discutir e se posicionar. Nessa situação possuem a oportunidade de denunciar, cobrar e solicitar pessoalmente às representantes suas demandas.

Além do diálogo em Audiência, o Projeto de Lei no 1844/2016 - sobre publicidade sexista -, destaca-se por apresentar na sua justificativa outra forma de contato entre representantes e eleitorado.

A informação de que ele decorre de uma construção coletiva com a UBM demonstra que as parlamentares se preocuparam em dialogar com movimentos sociais e, neste caso, não apenas um movimento mulheres, mas um movimento que se declara feminista.

A UBM, União Brasileira de Mulheres, é uma entidade feminista nacional ${ }^{8}$ - com núcleos em diferentes cidades -, sem fins lucrativos, que atua no fortalecimento dos direitos das mulheres, desde a sua criação em 1988 e possui frentes de atuação tanto individuais - em atos, formações, reuniões, entre outros -, quanto junto à órgãos e parlamentares, por meio de consultas e propostas (Rangel 2012).

A atuação da UBM também demonstra a contrapartida do eleitorado para a representação positiva da parlamentar, pois "os membros do eleitorado são mais bem representados quando se organizam para discutir suas concordâncias e diferenças uns com os outros e com os representantes" (Young 2006: 173).

Assim, as críticas que cabem à superficialidade e ao baixo número das proposições, não devem ofuscar a importância de ter temas como esses debatidos dentro da ALERJ.

O contexto de retirada de direitos básicos das mulheres; violência misógina explícita e legitimada e; o pequeno número de deputadas na Casa refletem que esses poucos Projetos de Lei e temas abordados significam tanto a resistência das deputadas em propô-los quanto a riqueza da modalidade de Audiência Pública por permitir essa dinâmica acontecer.

Da mesma maneira, o número baixo de Projetos de Lei e Leis com temas relacionados à Audiências Públicas aqui apresentado, não significa que não há outras propostas e leis com os mesmos temas abordados em Audiências Públicas em outros períodos da legislatura. $\mathrm{O}$ fato a ser

\footnotetext{
${ }^{8}$ Para saber mais sobre a UBM e outros movimentos nacionais feministas consultar a pesquisa de Patricia Rangel em: RANGEL, P. D. Movimentos feministas e direitos políticos das mulheres: Argentina e Brasil. 2012.
} 
destacado é que a "utilidade" da Audiência Pública se aproxima da ideia de um espaço de formação. Oportunidade em que as parlamentares aprendem sobre temas aos quais elas não têm, ou tem pouca, atuação parlamentar.

Conforme as atas das reuniões da CDDM, verifica-se que a maioria dos temas de Audiência Pública são propostos pela presidenta da CDDM, deputada D. A entrevistas com as suas assessoras demonstrou que as demandas por audiências públicas chegam tanto por meio das demandas da CDDM, quanto de movimentos feministas.

Tento em vista que ambas a assessoras responsáveis pela CDDM, em nome da presidenta, fazem parte do movimento feministas UBM, é possível inferir que as pautas também possuem uma perspectiva feminista.

Isso pode ser um dos motivos que explique a distância entre os temas das Audiências e das Legislações. A realização da Audiência possui um crivo mais flexível do que a propostas legais, também dependem menos da articulação com parlamentares e não tem um rito longo para sua realização.

Assim, afloram as contradições sobre os temas e legislações decorrentes das audiências Públicas realizadas, presididas e compostas pelas mesmas parlamentares.

\section{CONSIDERAÇÕES FINAIS:}

Se propor a pensar a produção legislativa para mulheres por meio da atuação parlamentar e, a partir de uma perspectiva feminista, analisar a relação com as Audiências Públicas, resultou na necessidade de pensar e firmar diversos aspectos, antes mesmo de olhar para o extrato da realidade delimitado pela pesquisa.

Uma primeira questão é a desconexão entre a produção legislativa e a representação por perspectiva: ainda que todas as deputadas tenham produção legislativa especificamente direcionada às mulheres, quando o tema é derivado e direcionado pelas discussões realizadas nas Audiências Públicas, a propositura legislativa é bastante baixa (dois projetos da mesma deputada e dois projetos coletivos). Desta forma, a representação por perspectiva, que teria nas Audiências Públicas um espaço privilegiado para sua realização, não se concretiza.

Assim essa análise demonstra que tanto a realidade quanto as propostas teóricas refletem importantes potencialidades e limites na atuação parlamentar de mulheres.

As diferentes formas das deputadas representarem demandas de mulheres não se trata de uma novidade ou limite da realidade. Ela somente reforça que o olhar essencialista sobre a prática política não consegue corresponder à pluralidade, que é inerente a ela, ainda que se trate de um grupo todo formado por mulheres. 
Por todos esses motivos, é possível pensar a função destas Audiências Públicas ${ }^{9}$ como um momento de contato com temas e pessoas: as audiências são realizadas, os temas são debatidos e a população tem espaço para fala. Mas isso não se transforma em proposições legais.

Disso é possível perceber que a organização das audiências por membras dos movimentos feministas e mesmo a presença e fala de militantes feministas, não é capaz de gerar ações legislativas.

Isso, no entanto, não significa irrelevância das audiências. Para além dos dados de pouca relação com as proposições legais, verificou-se que é por meio das Audiências públicas que três situações importantes ocupam o parlamento: a) temas "tabus" são levados à discussão; b) as deputadas são informadas sobre assuntos dos quais não possuem bagagem teórica e política e; c) especialistas, militantes e sociedade civil têm a oportunidade de cobrar diretamente de parlamentares mulheres, mais responsabilidade política com questões que perpassam suas semelhantes.

Assim, verificou-se que as Audiências Públicas são mais um espaço que reflete o movimento de tensão dos direitos das mulheres, que passa por uma vigilância permanente das vias burocráticas e institucionais, por onde eles são debatidos, construídos, retirados e também insivibilizados.

Considera-se, pois, que também faz parte do processo de luta reconhecer que a política institucional precisa ser conhecida e analisada pelos movimentos feministas. Nesse sentido, pesquisar direitos das mulheres através de um campo que não é receptivo às lutas de mulheres $\mathrm{e}$ feministas foi também uma maneira de construir um panorama, para se pensar nas brechas pelas quais as lutas das mulheres podem se infiltrar.

\section{REFERÊNCIAS:}

ALMEIDA, Silvio Luiz de. 2018. O que é racismo estrutural? Belo Horizonte (MG): Letramento. Assembleia Legislativo da Estado do Rio de Janeiro. 11 a Legislatura. Disponível em: <http://www.alerj.rj.gov.br/>. Acesso em 4 maio 2019.

FIGUEIREDO, Argelina Cheibub; LIMONGI, Fernando. 2001. Executivo e legislativo na nova ordem constitucional. Rio de Janeiro: Ed. FGV.

FRASER, Nancy. 2015. Fortunas del feminismo. Madrid: Traficantes de Sueños.

ROSEGUINI, Guilherme. Mulheres são maioria nas Olimpíadas. G1, Jornal hoje, Rio de Janeiro, 05 ago. 2016. Disponível em: <http://g1.globo.com/jornal-hoje/noticia/2016/08/mulheres-sao-maioria-naolimpiada.html>. Acesso em: $15 \mathrm{dez} 2018$.

\footnotetext{
${ }^{9}$ São elementos importantes as limitações propositais e estruturais das Audiências Públicas, como o local de realização (tendo em vista que sempre ocorre na ALERJ e nunca numa área periférica), o horário (dentro do período "comercial") e baixa divulgação da atividade.
} 
Instituto Brasileiro de Geografia e Estatística. População. Disponível em: <https://ibge.gov.br/>. Acesso em 07 jul 2018.

Inter-Parliamentary Union. Women in national parliaments. Disponível em:

<http://www.ipu.org/wmn-e/classif.htm>. Acesso em 07 jul 2018.

PHILLIPS, A. De uma política de idéias a uma política de presença? 2001. Revista Estudos Feministas, v. 9, n. 1, p. 268-290.

RUBIM, Linda e ARGOLO, Fernanda (Orgs). 2018. O Golpe na perspectiva de Gênero. Salvador: Edufba.

SOUZA, Carlos Augusto da Silva; CAVALCANTE, Maria Jeane da Silva. 2012. Padrões geográficos das coligações eleitorais no Brasil: uma análise pela perspectiva ideológica dos partidos políticos - 2002 e 2006. In: ENCONTRO ANUAL DA ANPOCS, 36., 2012, Águas de Lindóia. Anais Águas de Lindoía.

Tribunal Superior Eleitoral. Eleições. Disponível em:

<http://www.tse.jus.br/eleicoes/estatisticas/eleicoes/eleicoes-anteriores>. Acesso em: 15 maio 2018.

YOUNG, I. M. 2006. Representação política, identidade e minorias. Lua Nova: Revista de Cultura e Política, (67). 139-190.

YOUNG, Iris Marion. 2000. Inclusion and democracy. Oxford series in political theory. Oxford: Oxford University.

\section{AUTORA:}

\section{Naiara Coelho}

Mestra do Programa de Pós-Graduação em Sociologia e Direito da Universidade Federal Fluminense, bolsista CAPES.

E-mail: nc.naiaracoelho@gmail.com 